Pedagogía y Saberes n. ${ }^{\circ} 54$

Universidad Pedagógica Nacional

Facultad de Educación. 2021. pp. 23-36

\title{
Panglotia, pampedia y pansofía: el realismo pedagógico en Comenio
}

\section{Panglottia, Pampedia and Pansofia: The Pedagogical Realism in Comenio \\ Panglottia, pampedia e pansofia: realismo pedagógico em Comenius}

\author{
Andrés González Novoa* \\ Pedro Perera Méndez**
}

González-Novoa, A. y Perera-Méndez, P. (2021). Panglotia, pampedia y pansofía: el realismo pedagógico en Comenio. Pedagogía y Saberes, (54). https//doi.org/10.17227/pys. num54-11286

* Doctor en Educación. Profesor asociado de la Universidad de la Laguna. Correo: agonzaln@ull.edu.es

Código Orcid: https://orcid.org/0000-0003-2578-8888

** Doctor en Educación. Ayudante Doctor en la Universidad de la Laguna.

Correo: ppereram@ull.edu.es

Código Orcid: https://orcid.org/0000-0002-2065-1711 


\title{
Resumen
}

Este trabajo resulta de una revisión parcial de la obra de Juan Amos Comenio, quien vertebró el realismo pedagógico desde una antropología del exilio. De los más de doscientos textos del moravo se han seleccionado y estudiado aquellos que reflejan tres de las líneas fundamentales para comprender la Didáctica magna como un artificium docendi destinado a imaginar una educación para todas y todos en todo. La primera línea se centra en las obras que abordan la enseñanza de la lengua latina a través de las lenguas vernáculas y su inacabado sueño de arribar a la panglotia, la lengua universal. Seguidamente se analizan los textos pedagógicos-didácticos que establecerían el mesocentrismo para un magisterio capaz de formar, más que de instruir en un saber universal: la pampedia. Y finalmente, se abordan los trabajos orientados a la reforma social que revisan hondamente los principios del humanismo para vindicar una fraternidad que precisa del Homo viator, del huésped del mundo. Un extenso trabajo que transita desde la pansofía hacia la panharmonía, entre la intuición de los principios democráticos de la consulta universal y los imprescindibles discursos contra los populismos para el debilitamiento de los prejuicios. Las tres líneas se desarrollan en el paradigma mecanicista-teleológico generando un diálogo entre tradición y modernidad que establece en la obra de Comenio un equilibrio entre la inmanencia y la trascendencia y la torna en una posada donde se encuentra el sistema tradicional y el sistema liberal de enseñanza; un zaguán donde el magicentrismo y el paidocentrismo conviven bajo la disciplina del método.

\section{Palabras clave}

pedagogía social; didáctica; educación para la paz; educación permanente; enseñanza de lenguas

\begin{abstract}
This paper is derived from a partial review of the work of Juan Amos Comenio who structured the pedagogical realism from an anthropology of exile. Of the more than two hundred texts by the Moravian those that reflect three of the fundamental lines to understand the Didactica Magna as an artificium docendi destined to imagine an education for all in everything have been selected and studied. The first line focuses on the works that address the teaching of the latin language through the vernaculars and their unfinished dream of arriving at panglotia, the universal language. Next, we analyze the pedagogical-didactic texts that would establish the mesocentrism for a teaching staff capable of forming, rather than instructing in a universal knowledge: the pampedia. And finally, the works oriented to the social reform that revise deeply the principles of the humanism to vindicate a fraternity that needs the Homo viator, the guest of the world, are approached. An extensive work that moves from pansophy to panharmony, between the intuition of the democratic principles of universal consultation and the indispensable discourses against populisms for the weakening of prejudices. The three lines are developed in the mechanicist-teleological paradigm, generating a dialogue between tradition and modernity that establishes, in the work of Comenio, a balance between immanence and transcendence and turns it into an inn where the traditional system and the liberal system of education are found; a hallway where magicentrism and paidocentrism coexist under the discipline of the method.
\end{abstract}

\section{Keywords}

social pedagogy; didactics; education for peace; lifelong learning; language teaching

\begin{abstract}
Resumo
Este trabalho é uma revisão parcial do trabalho de Juan Amos Comenio que estruturou o realismo pedagógico a partir de uma antropologia do exílio. Dos mais de duzentos textos do Morávio, foram selecionados e estudados aqueles que refletem três das linhas fundamentais para entender a Didactica Magna como artificium docendi destinado a imaginar uma educação para todos e todas em tudo. A primeira linha centra-se nas obras que abordam o ensino da língua latina através das línguas vernáculas e o seu sonho inacabado de chegar à panglotia, a língua universal. Em seguida, são analisados os textos pedagógico-didácticos que estabeleceriam o mesocentrismo para um corpo docente capaz de formar, em vez de instruir num conhecimento universal: a pampédia. E finalmente, são abordados os trabalhos orientados para a reforma social que revêem profundamente os princípios do humanismo para justificar uma fraternidade que necessita do Homo viator, o convidado do mundo. Um extenso trabalho que passa da pansofia para a panharmonia, entre a intuição dos princípios democráticos da consulta universal e os discursos indispensáveis contra os populismos para o enfraquecimento dos preconceitos. As três linhas do trabalho baseiam-se no paradigma mecanicista-teleológico, gerando um diálogo entre tradição e modernidade que estabelece, na obra de Comenio, um equilíbrio entre imanência e transcendência e a transforma em uma pousada onde se encontram os sistemas educativos tradicional e liberal; um saguão onde a magicentrismo o paidocentrismo coexistem sob a disciplina do método.
\end{abstract}

\section{Palavras-chave}

pedagogia social; didáctica; educação para a paz; aprendizagem ao longo da vida; ensino de línguas 


\section{Panglotia, pampedia y pansofía: el realismo pedagógico en Comenio}

La negación de la herencia siempre me ha parecido

tónica y estimulante. Pienso, no obstante, que para negar hay que conocer primero aquello que se niega [...] No

digo que los jóvenes deban continuar, repetir o imitar

a sus predecesores; digo que toda negación, si no es un grito en el vacío, implica una relación polémica con aque-

llo que se niega. No me preocupa la rebelión contra la tradición: me inquieta la ausencia de tradición.

Octavio Paz, La búsqueda del comienzo.

La obra del moravo comprende más de doscientos textos que abarcan tratados sobre física, estudios para el control de epidemias, ensayos sobre política, literatura, obras de teatro, manuales de lingüística, obras didácticas, teorías educativas, críticas sobre teología, historia de las religiones, investigaciones sobre mecánica... (Lora, 1997). Tal amplitud de temáticas y tal magnitud de empresas serán producto de un ethos ordenador que responde en el siglo XVII al marasmo espiritual en el que está sumida Europa y concretamente su corazón: la Bohemia, que verá cómo más de la mitad de la centuria pasa en un escenario bélico donde se construirá reactivamente una antropología del exilio.

Para el análisis de tan vasta obra, y basándonos en la clasificación realizada por Federico Gómez Rodríguez de Castro $^{1}$ en su prólogo a El laberinto del mundo y el paraíso del corazón, nos centraremos en los escritos relacionados con la enseñanza de la lengua latina a través de las vernáculas, ${ }^{2}$ la reforma social y los textos pedagógico-didácticos, como se puede observar en la figura 1.

1 Dejando, por considerar ajenos a los principios de esta investigación, aquellos escritos sobre religión o sobre la historia de la Unitas Fratum, los cuales sirvieran de crítica intencionada y arbitraria para el enciclopedista Pierre Bayle — precursor del movimiento ilustrado- que en su Diccionario histórico y crítico (1695) exagera la polémica relación del moravo con las creencias milenaristas y sus vínculos con los profetas de la Bohemia. En cambio, Johan Gottfried Herder (1744-1803), autor de Ideas para la filosofía de la historia de la humanidad (1793-1798) posibilita una relectura más amplia que permitirá nuevas líneas de investigación en el trabajo posterior de Jan Patočka (1907-1977).

2 La palabra proviene del latín vernaculus, que significa 'nacido en la casa de uno', proveniente de vern, un esclavo nacido en la casa del amo. Para evitar la asociación anacrónica con la esclavitud en pleno siglo XVII, preferimos la expresión que propiamente utiliza el mismo Comenio: lenguas comunes o patrias.

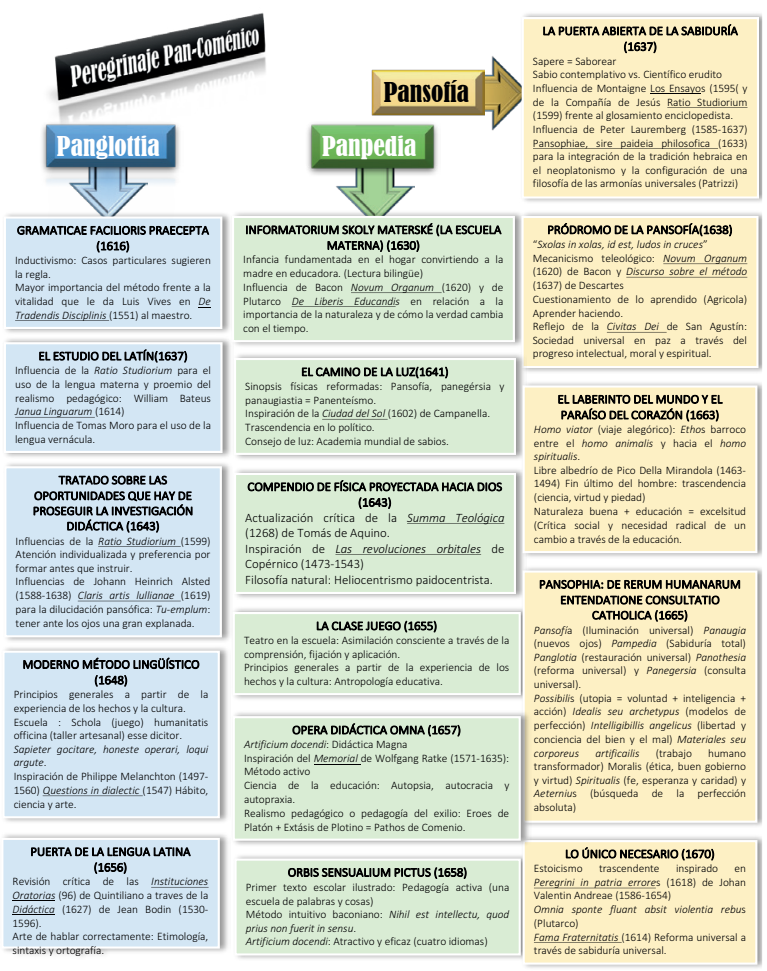

Figura 1. Cartografía comeniana

Fuente: elaboración propia.

Comenio trabajará, el primer tercio de su vida, en el corazón del Sacro Imperio Germánico, eje de las disputas religiosas entre católicos y protestantes, en el seno de la Unitas Fratum (husismo moderado inspirado en el pensamiento pacifista de Pedro Chekcky, pater del primer movimiento reformista de Europa, la Iglesia Checa Reformadora de 1467). Entre los años 1605 y 1606 presencia la invasión húngara, proemio de lo que será una constante vital para el moravo, el peregrinaje, la permanente sensación de éxodo, al punto de que se nomine su obra como la pedagogía del exilio (Seijas, 1991).

Su amplia formación en las universidades de Herborn y Heidelberg ${ }^{3}$ (1611-1614) le hará reaccionar contra la enseñanza memorística, considerándola, sobre todo, una pérdida de tiempo. Los tres pilares que sustentan su positiva aportación son: Sobre la naturaleza de los dioses de Cicerón acerca de la poderosa analogía entre naturaleza y el desarrollo del niño; el Memorial de Ratke, en el que entenderá el método como un valor universalizable - contrario a la defensa vivesiana del maestro- en el sendero hacia el

3 Allí conocerá la Fama Fraternatis de los rosacruces y tendrá las primeras ideas sobre los proyectos de reforma universal a partir de la difusión de la sabiduría universal. 
perfeccionamiento del hombre; y como tercer vértice, la obra de Nicolás Copérnico Sobre las revoluciones de las orbes celestes (1543), donde hallará la teoría heliocéntrica como metáfora para considerar al método el eje en torno al que deberá rotar el sistema educativo.

Si aquello que recibe apoyo de la tierra a través de las raíces vive y prospera gracias a una actividad artística de la Naturaleza, seguro que la tierra misma es sostenida, con idéntica fuerza, por el arte de la Naturaleza. (Cicerón, 1999, p. 83)

Su mesocentrismo inspira los trabajos reorganizativos de Sturm y Ramus (gradación, secuencia y sistematización), que suponen metodológicamente un atajo que confluirá en la primera obra del moravo: Reglas gramaticales más fáciles (1616), en la que corona un proceso iniciado por Quintiliano en las Instituciones oratorias, superando práxicamente el Ars Minor de Donato y enfrentándose a la metodología memorística del escolasticismo. Este trabajo, desarrollado sobre el inductivismo que se ha extendido en Europa, a través del empirismo y del mecanicismo, será la base de una de las obsesiones pansóficas de Comenio, la optimización de un método de enseñanza de las lenguas que prologase la panglotia, el lenguaje universal.

\section{Panglotia: desde lo vulgar hacia lo universal}

Comenio no logró su objetivo, pero lo esencial de sus ideas se conserva en dos tratados manuscritos redactados en 1665 que han permanecido inéditos hasta hace unos años (Cervenka y V. T. Miskovska 1996). En el primero (Panglottia), citando a Dalgarno, esboza una serie de reglas para construir una lengua universal: "tantas cosas, tantas palabras; una cosa simple, una palabra simple; una cosa compuesta, una palabra compuesta" (1966, t. II: 183). [...] Trata también la posibilidad de que los sonidos tengan una significación natural, idea que ya había sugerido Mersenne (1637) y puesto en práctica Sir Th. Urquhart en Logopandecteision (1653). (Galán Rodríguez, 2009, p. 108)

Con la muerte de su familia por la peste y la Guerra de los Treinta Años devastando su hogar, inicia su exilio en la Escuela de Gramática de Levno (1628-1632). La batalla de Montaña Blanca supone la derrota y persecución de los protestantes y los paisajes descubiertos en su éxodo lo hacen enfrentarse a católicos y luteranos al defender que el primer deber del hombre es comer, antes de ser cristiano. Allí, continuará investigando y enseñando sobre la línea de la panglotia, generando inicialmente textos de enseñanza del latín a través de la lengua común. En este proceso conocerá la obra del jesuita irlandés William Batheus, Janua Linguarum (1614). El texto muestra que, ajenos al presente jesuita, los principios de la Ratio Studiorium son la mejor síntesis educativa para la superación de los anacronismos escolásticos. Aristóteles, defenestrado por el siglo XVII, desde su Organum y a través de Philippe Melanchthon, recupera su vigor al ser reinterpretado como una magnífica plataforma epistemológica para la organización curricular de una escuela que tuviera como objetivos la extensión de una sabiduría enciclopedista. Comenio desarrolla su Puerta abierta de las lenguas (1631), bilingüe, partiendo de la lengua común hacia el latín, desde la herencia jesuita de que el maestro debe atender las necesidades individuales del alumno y sobre la máxima de formar antes de instruir.

\begin{abstract}
Además, cuando los que tienen una constitución tan mala dicen sus malos proyectos políticos y sus discursos en las ciudades, en privado y en público y, por otro lado, cuando tampoco se estudia en absoluto desde joven aquello que pueda servir de remedio a esto, todos los malos nos hacemos malos por dos motivos involuntarios, de los que siempre hay que culpar más a los que engendran que a los que son engendrados y a los que educan, más que a los educados. Sin embargo, hay que procurar, en la medida en que se pueda, huir del mal y elegir lo contrario por medio de la educación y la práctica de las ciencias. (Platón, 2003, pp. 51-52)
\end{abstract}

Se halla ya inserto en una red de pensadores y de sociedades que suscriben la máxima del Timeo que confía en que para toda perturbación del orden existente hay remedio (Platón, 2003). Recibe ofertas del cardenal Richelieu para desarrollar una escuela pansófica e incluso se encuentra con Descartes para comprobar lo complejo que es conciliar el pansofismo con el racionalismo. Sin embargo, siguiendo esta primera línea de libros sobre la didáctica del lenguaje, en 1643 se publica el Tratado sobre las oportunidades que hay de proseguir la investigación didáctica. Aparece cada vez con más fuerza la autopsia, autocracia y autopraxia de Ratke, pero esta vez, integrados en el unitarismo epistemológico platónico de Raimundo Llull (1235-1315) a través de la obra enciclopedista de John Heinrich Alsted, Clavis Artis Lullianae (1619), donde el modelo de escalas configura un sendero de perfeccionamiento que parte de la síntesis de la tradición para restaurar el orden. Dicha dilucidación pansófica se fundamenta en el concepto de vacío desarrollado por Blaisse Pascal (1623-1662) que rescatará el sentido de Tu-emplum: tener ante los ojos una explanada. 
Todo lo que existe tiene grados distintos y claros en su ser. Estos, observados como se debe, conducen a la mente en todos los puntos primeros y últimos, los más bajos y los más altos. [...] Tal graduación que conduzca a la mente a la adquisición de todo conocimiento, confiamos que se encuentre en nuestra Pansofía, tanto en su conjunto como en cada cosa en particular. (Lora, 1997, p. 106)

La defensa del latín que encarnarán los jesuitas, y en la que también encontramos a Comenio, no es únicamente un intento de conservar la tradición o mantener el statu quo, pues frente al caótico escenario que han generado las disidencias políticas y religiosas, existe una intención colectiva, desde la jerarquía, de poner freno al panorama fragmentario europeo a través el control y la vigilancia; y ello, conduce a que la extensión de centros educativos que promulguen el latín como idioma de la sabiduría les conduzca a peligrosas estrategias como la de enseñarlo a través de las propias lenguas comunes que lo amenazan.

Se ha establecido que el Papa, los obispos, los sacerdotes y los monjes sean llamados el estado eclesiástico; y los príncipes, los señores, los artesanos y los agricultores, el estado secular. Es una mentira sutil y un engaño. Que nadie se asuste y esto por la consiguiente causa: todos los cristianos son en verdad de estado eclesiástico y entre ellos no hay distingo, sino solo a causa del ministerio, como Pablo dice que todos somos un cuerpo, pero que cada miembro tiene su función propia con la cual sirve a los restantes. Esto resulta del hecho de que tenemos un solo bautismo, un Evangelio, una fe y somos cristianos iguales, puesto que el bautismo, el Evangelio y la fe de por sí solas hacen eclesiástico y pueblo cristiano. (Lutero, 1986, p. 41)

Tras la carta abierta de Lutero (1520), comenzarán a surgir proyectos convencidos de perfeccionar al hombre a la altura de la naturaleza; incluso más, desde las mismas lenguas comunes. Y en el seno del conflicto lingüístico, las Questions in dialectic (1547) de Philippe Melanchthon ampliarán la Ratio Studiorium junto a una sólida cultura clásica de corte neoplatónico. En dicha obra se integran hábito, ciencia y arte como respuesta a unos studia humanitatis que se entienden poco adecuados para el tiempo de la manufactura. Tal inspiración será recogida en Moderno método lingüístico (1648) junto a la herencia de Michel de Montaigne y su desarrollo a través del empirismo baconiano. Los principios generales se obtendrán a partir de la experiencia de los hechos y la cultura. La schola (juego) será la humanitatis officina (taller artesanal) esse dicitor (para hablar correctamente). Y ese hablar correctamente que poco tendrá que ver con el del retórico platónico o el orador ciceroniano, quizás mucho más con el apparitor de Quintiliano, quedará resumido en el sapienter cogitare, honeste operari, loqui argute (con sabiduría pensar, con honestidad actuar y hablar con propiedad). Es decir, que en la profundidad evolutiva de Comenio, en el plano de la didáctica de la lengua, van a imponerse en defensa de la unidad religiosa, curiosamente, los principios empírico-mecanicista por encima de los teleológicos.

Esto queda evidenciado en la última obra de la categoría lingüística que escribirá en 1656, Puerta de la lengua latina, en la que reflexiona, desde una revisión crítica de las Instituciones oratorias, a través del trabajo Didáctica de Jean Bodin, para sentenciar que hablar correctamente será la capacitación instrumental etimológica, sintáctica y ortográfica.

Cuando las cosas estén enmendadas de tal manera que lo tengamos todo de verdad universal, la filosofía, la religión y la política; los eruditos tendrán oportunidad de colegir y depurar las verdades e inculcarlas en la mente humana; los sacerdotes, de arrancar las almas del mundo dirigiéndolas hacia Dios; los políticos, de preservar en todas partes la paz y tranquilidad; exhortándose a la emulación con santo celo, para que cada uno en su puesto promueva excelentemente al bienestar de la prole humana. (Comenio, 1996, p. 79)

Así, queda resumida la obra del moravo en relación a la enseñanza de la lengua latina a través de las comunes; su proyecto de panglotia que debía cimentar la panorthosia (restauración universal) - excesivamente anclada al latín- no podrá hacer frente a la extensión y elevación a lenguajes de saber de las lenguas comunes.

La obra pedagógica, que iniciará con La escuela materna (1630) y que compendiará en su Opera Didáctica Omnia (1657) junto con los libros escolares y el proyecto de un sistema educativo pansófico, quedará perfectamente sintetizada y organizada en la Didáctica magna.

Situado en pleno proceso de expansión y competencia de poderes emergentes y fragmentarios, inserto en el desarrollo de una nueva maquinaria productiva y en el umbral del establecimiento - ya iniciado en el Renacimiento- de la inmanencia en el plano de la superestructura social — sobre todo, gracias a los aportes calvinistas y puritanos-, Comenio entenderá como fundamental la vocación de mecanizar los instrumentos de transmisión y unificación del cristianismo para reaccionar a la fragmentación del mundo.

Es digno de estudio, sin embargo que, siendo un adversario contextual de los jesuitas, conforme junto a ellos la matriz coherente para la defensa del 
concepto de tradición como fuente de metaproyectos civilizatorios. Dentro de este marco, y paralelo al deseo de Quintiliano de estabilizar la producción de apparitores para un proyecto homogeneizador a través de una clara división social del trabajo, Comenio entiende que el proceso educativo debe rentabilizarse con la idea de que, en el menor tiempo posible, pueda ofrecer hombres útiles para la creación, mantenimiento y desarrollo de una comunidad cristiana establecida en clave manufacturera.

Apuntala los principios que ha de consolidar, un siglo más tarde, el naturalismo pedagógico al instalar su obra sobre la creencia de que el ser humano posee una actitud innata para aprender, de lo cual emana que educar es el arte del jardinero que acompaña a la naturaleza proveyendo al alumno de experiencias novedosas y estimulantes que germinen las semillas interiores (Comenio, 1991). Por lo que siguiendo el constante símil con el crecimiento y el cultivo de las plantas, cuanto más y mejor empeño se ponga en los primeros años - "solamente es firme lo que en la primera edad se aprende" (Comenio, 1996, p. 14)—, más rápido y mejor predisposición tendrá el alumno en los siguientes.

Dividiendo el viaje educativo en cuatro etapas, inicia su odisea desde su primer tratado pedagógico —el anteriormente mencionado La escuela materna - en el que describe y detalla cómo han de ser los primeros seis años de vida. Concibe a la madre como una educadora que manipula y orienta sanamente el desarrollo del cuerpo y estimula correctamente los órganos sensoriales. Es decir, ajusta la maquinaria humana al emergente paradigma sensorio-mecanicista y a una nueva estructura del conocimiento enciclopedista.

La lengua materna es el punto de partida de una vertiginosa carrera tras una verdad que muta constantemente. Es aquí donde se cocina el sentido profundo del realismo pedagógico. Consciente de la naturaleza precapitalista de su tiempo y de la extensión de la inmanencia en el imaginario occidental, será el tiempo el eje que seleccionará los mecanismos y que marcará la gradual aniquilación de los excesos de equipaje.

Un método único, un mismo docente, manuales universales, arquitectura escolar, grupos homogéneos, secuenciación, implicación de los padres, supresión de la división sexual de la educación... dan la sensación de primar la rentabilidad que subyace a una mirada resignada, y por tanto realista, más que un proyecto de máximos como pudiera parecer la Ratio Studiorium jesuita (Belenguer y González, 1988).
Un proyecto, sin embargo, ambicioso, que requería de la implicación de las administraciones públicas y que debía apuntar a una reforma moral, política y cristiana de la humanidad. De ahí que sea importante entender como un deber el acto humano de aprender, una responsabilidad para y con la comunidad a la que se pertenece. Esta idea, que posteriormente hará general y universal Kant, será el corolario del proceso de emancipación intelectual que arrancará en el Renacimiento frente al paternalismo monárquico y divino. La libertad ya no es un derecho divino, ni un golpe de fortuna, tampoco una herencia lineal; la libertad que se intuye en la centuria previa de las revoluciones racionales es una losa moral y un desafío fundamental en el acto socrático de conocerse a uno mismo.

\section{Pampedia: la educación para todas y todos en todo}

La pampedia es un proyecto homogenizar fundado en un modelo escolar inclusivo, dotado de recursos y criterios para el acceso y el desempeño del alumnado a pesar de sus circunstancias, como se observa en su obra La escuela materna con la introducción de las ayudas escolares. El proyecto pedagógico de Comenio se anticipa a una sociedad de obreros instrumentalmente capacitados y cinturones de herrumbre en torno a los núcleos industriales; y Comenio lo percibe desde el descontento que provocan las instituciones eclesiásticas y en sí los Montes de Piedad que, como ya denunciara Nicolás de Cusa, se maquillan de profundo humanitarismo cuando sus rostros esconden absoluta indiferencia.

El maestro, uno para cada grupo, sin ser tan vital como lo describiera Juan Luis Vives en el Tratado de las disciplinas (1531), se convierte en un mediador-modelo que sobre todo conoce en profundidad la idiosincrasia del método y está capacitado para usar los materiales y los mecanismos didácticos en el momento oportuno y cuando el alumno lo necesita. Básicamente, el maestro comeniano será un instrumento didáctico objetivamente perfecto, que enseñará demostrando, haciendo las cosas al mismo tiempo que las explica y luego acompañando y reorientando al alumno mientras este las desarrolla.

En el segundo lugar, después de estos, has de tener a tus maestros, a tus ayos, a tus tutores, y finalmente a aquellos que han tenido cargo de tus costumbres, que son la cosa más preciosa y más excelente que hay en el hombre. (Vives, 2010, p. 41) 
Este modelo de magisterio, heredado de su experiencia en la escuela calvinista de Herborn y detallado en la actualización lulista de Alsted, será un Minister Naturae, restaurador, cuyo ethos ordenador ha de ser la disciplinarización de los alumnos para el mantenimiento de los nuevos instrumentos de vigilancia que requerirá el Estado moderno. Debe entonces tener la autoridad y la destreza para captar el interés de los discípulos a través de los sentidos y desarrollar dicha atención mediante el manejo secuencial y dinámico de los recursos didácticos puestos a dicho servicio.

El método que el maestro ha de ejecutar en estricta disciplina será desarrollado a profundidad en su Didáctica magna. Anteriormente, el Tratado sobre las oportunidades que hay para proseguir la investigación didáctica (1643) ya plantea, en su fluctuación entre el mecanicismo y el paradigma teleológico (Belenguer y González, 1988), que el método como imitación de la naturaleza debe ser único y que, acorde al sensualismo, racionalismo y misticismo, irá de lo conocido a lo desconocido, de lo simple a lo complejo, de lo concreto a lo abstracto; una filosofía natural que intenta superar el aristotelismo jesuita pero sin cuestionar el resto de su esqueleto educativo, pues si bien defiende un modelo cariñoso y lúdico, no veta e incluso define con exactitud, como lo hiciera la Compañía de Jesús, el uso y los modos del castigo para el mantenimiento estricto de la disciplina.

Tal es la influencia discreta de los jesuitas que hasta el teatro que introducen en sus escuelas como método para la comprensión experiencial de las ideas y los caracteres conforma la esencia de la obra La clase juego (1655). En esta, el teatro es el recurso didáctico para la asimilación consciente a través de la comprensión, la fijación y la aplicación. Así, al modo baconiano, los principios generales parten de la experiencia de los hechos y la cultura, conformando las líneas fundamentales de una antropología educativa paidocéntrica y homogeneizadora.

Si bien los mismos jesuitas mostraron cierta desconfianza hacia los libros y su pandémica extensión a través de la imprenta, nunca tuvieron la fobia que evidenciaría el moravo hacia la sólida cultura clásica. El mecanicismo y la necesidad del viajar ligero de equipaje epistemológico en un mundo que requiere de los ojos limpios y las manos abiertas conducirán a la necesidad y también a la acción de desarrollar manuales y libros escolares que respondan a través del enciclopedismo a las urgencias psicológicas del niño. Así surgirá El mundo ilustrado en imágenes (1658) en el que se condensan la mayor parte de los avances tecnológicos de su tiempo al servicio de la educación y que introduce de la siguiente manera:
"El libro es pequeño, como se puede ver. Sin embargo, es un breviario de todo el mundo y de la lengua toda, lleno de imágenes, nombres y descripciones de cosas" (Comenio, 1993, p. 72).

Esta obra, considerada el primer manual audiovisual fundamentado en una pedagogía activa para una escuela de palabras y cosas, es el resultado de una metodología que prima la observación como medio para la asimilación del conocimiento que ofrece el mundo. El nihil est intellectu, quod prius non fuerit in sensu (no hay nada en el intelecto que no estuviera antes en los sentidos) (Aquino, 2005, p. 70) tomista-baconiano al servicio escalonado de las condiciones individuales del alumno decanta y sentencia al latín, dando primacía a las lenguas comunes. No obstante, el tiempo y la eficacia son las constantes que van a estructurar un sistema operativo de talleres de humanidad como punto de partida hacia una compleja idea de educación permanente.

El mundo ilustrado en imágenes, sin embargo, será el modelo referente, la fracción de una guía didáctica que, inserta en el molde de la Enciclopedia, debía dar al maestro y al alumno, de forma ordenada, los conocimientos y prácticas adecuadas a cada edad; eficacia inserta entre perder el tiempo para ganarlo o ganar tiempo para perderlo. Tan peligroso es el analfabetismo como una educación permanente institucionalizada, por tanto, el justo medio es una enseñanza eficaz que libere al hombre para la acción en el momento oportuno.

Su reflexión invita a pensar sobre el porqué de tanta incidencia en la educación temprana, tanto detalle en la formación del adolescente y tanto esbozo idealista en el aspecto aristocrático o elitista de dicho proceso en torno a la adquisición, el mantenimiento y el desarrollo del saber intelectual. En El camino de la luz (1641), donde ya están adscritos los conceptos de pansofía, panegersia y panaugiastia como pilares del panenteísmo, y siguiendo la línea de La ciudad del sol de Campanella y de la Nueva Atlántida de Bacon, solamente y a modo de utopía, aparecerá esbozado el Consejo de Luz, mímesis de la Casa Salomón, que representará a modo de recomendación la necesidad global de una academia mundial de sabios que oriente las decisiones de los rectores del mundo. La profunda trascendencia política, vital para una reforma social y moral, quedará sumergida en su ideario teleológico.

El artificium docendi, atractivo y eficaz, que conformará la Didáctica magna como método activo, en estas circunstancias, favorecerá una educación instrumental o laboral orientada a la capacitación rentable de futuros obreros; evolución en clave marxista de los esclavos de la edad antigua o de los vasallos en el Medievo. 


\section{Pansofía: el Homo viator como huésped del mundo}

El concepto de pansofía, que pergeña Peter Lauremberg (1585-1637) en su obra Pansophiae sive paideia philosophica para la integración de la tradición hebraica y el neoplatonismo, en el ejercicio de construcción de una filosofía de las armonías universales, aparecerá por primera vez en la obra de Comenio en 1637 en La puerta abierta de la sabiduría.

Es importante entender que el diálogo de Timeo de Platón será la inspiración para que Raimundo Llull genere un organicismo antiaristotélico y antiescolástico que será la plataforma en la cual Marsilio Ficino, Nicolás de Cusa y Giovanni Pico della Mirandola van a desarrollar el concepto de libre albedrío que desembocará en el proyecto pansófico (neoplatonismo, hebraísmo y cultura grecorromana) de Peter Lauremberg, Francesco Patrizi, Robert Fluud, Tommaso Campanella, Johann Valentin Andreae y Francis Bacon. Este es un proyecto en el que se van a fusionar la quiliástica, el hermetismo, el gnosticismo, la alquimia y la cábala.

En la primera obra de reforma social del moravo, la reflexión central va a girar en torno al concepto de sabiduría. La influencia de Michel de Montaigne y de la Ratio Studiorium de la Compañía de Jesús van a primar al sabio contemplativo, trascendente y reflexivo, experiencial y comunitario frente al pródigo científico erudito, acumulador y cuantificador de conocimiento. El moravo, analizando etimológicamente la propia palabra, extrae que sapere tiene un sentido palatino, de saborear, de madurar. Dicha acepción tiene sus analogías en el Nuevo Testamento y también en el pensamiento unitario de Platón, lo que delinea un boceto de sabiduría que no tiene fin en sí misma, sino el medio - o instrumento- para el perfeccionamiento de la naturaleza humana y de su mejor y más extensiva participación en la transformación de la sociedad que lo alberga.

Tales sensaciones cristalizarán en su obra Pródromo de la pansofía (1638). Analizando etimológicamente el título, encontramos que pródromo es el malestar que antecede a la enfermedad, lo cual resume la sensación de incertidumbre que se extendía por Europa ante lo que suponía la Paz de Westfalia y la pérdida del poder omnipresente de la Iglesia católica. Esta inseguridad paradigmática, avivada por la aparición de brotes vernáculos, empíricos y racionalistas, tiene su símil físico en la situación geopolítica y resulta extrapolable a la percepción que tuvo el mundo de Agustín de Hipona ante la entrada de Alarico y sus huestes en el oscurecimiento de Roma.
Que lo que hubo de rigor en la destrucción de Roma sucedió según el estilo de la guerra, y lo que de clemencia provino del poder del nombre de Cristo. Todo cuanto acaeció en este último saco de Roma: efusión de sangre, ruina de edificios, robos, incendios, lamentos y aflicción, procedía del estilo ordinario de la guerra; pero lo que se experimentó y debió tenerse por un caso extraordinario, fue que la crueldad bárbara del vencedor se mostrase tan mansa y benigna, que eligiese y señalase unas iglesias sumamente capaces para que se acogiese y salvase en ellas el pueblo, donde a nadie se quitase la vida ni fuese extraído; adonde los enemigos que fuesen piadosos pudiesen conducir a muchos para librarlos de la muerte, y de donde los que fuesen crueles no pudiesen sacar a ninguno para reducirle a esclavitud; estos son, ciertamente, efectos de la misericordia divina. (Hipona, 2006, p. 26)

La conmoción que supone la aparición de un modelo de trascendencia en las tinieblas, la incertidumbre que sucede a la caída del corazón de las certezas, la fragmentación o desestabilización de los espacios de confianza o de fe, provocan en el pensamiento inercias hacia la restauración (mirada idealizada del pasado) o hacia el escapismo (aniquilación del pasado y mirada taumatúrgica hacia el futuro).

En el umbral de ambas visiones, entre el pesimismo que transmite Inocencio III en De Miseria Humanae Conditionis y el optimismo de las utopías sensoempiristas, el concepto que va a describir y defender Comenio, el de pansofía, más práxico, contemplará al humano como mediador entre la jerarquía de los seres; concepto que habita entre la verdad revelada y develada, un macroántropos que se torna en la sombra alargada del antropocentrismo renacentista y que tiene como destino el restablecimiento del contacto primordial entre el mundo ideal y la realidad misma. Resume lo anterior expresando que: "Todas las cosas que existen integran el universo como un solo ser sin interrumpir en ningún punto la concatenación" (Comenio, 1996, p. 69).

Esta visión que hereda el siglo XviI de Nicolás de Cusa, ese hombre como cadena, nudo y cópula del mundo, esos grados de atributos de los seres de Raimundo Llull, se trasladan en lo epistemológico a los grados de saber y escalas del aprendizaje.

Consideramos que a esto tienden los diversos intentos de muchos de nuestra época, que reúnen el conocimiento en síntesis y divulgan pandectas, sinopsis, cuerpos, sumas, enciclopedias, etc., en los más diversos campos, la teología, la filosofía, el derecho, la medicina, y aún teatros de la sabiduría humana, transformaciones de las ciencias, Instauraciones magnae, omniscientiae christianae. 
Si el intento de ellos de poner en orden las cosas dispersas y llevar a la luz las cosas oscuras que no le agradan a las mentes buenas, ¿por qué debe desagradarnos formar a partir de todo una obra aún más general, más común y más adaptada a los fines universales? Ciertamente, los individuos recaban de las cosas la especie, de la especie el género, de los géneros el género más universal, del mismo modo la misma graduación de los conceptos de nuestro intelecto requiere que se reúnan los particulares en las sumas, y las sumas en la suma de las sumas. (Comenio, 1996, p. 70)

La constante relación macro-microcosmos convierte todo descubrimiento u observación del universo, de la naturaleza o de lo antes invisible, en una nueva definición o aplicación de lo humano en el constructo que supone la restauración universal.

Para que dicha relación sea posible o positiva, es fundamental que el hombre sea pansophicus, "también homo políticus, por cuanto su actividad filosófica no se separó de su actividad pública" (Lora, 1997, p. 133), y esté formado en una amplia poliglotía - lo cual ya estableció la Compañía de Jesús - o que la panglotia se tornase en un proyecto prioritario para los estamentos públicos.

Finalmente, ya que hemos comprendido que el único obstáculo, pero muy fuerte, para que esta luz penetre en las naciones, está constituido por la multitud, la variedad y la confusión de las lenguas, hemos osado tratar de remover este impedimento por medio de nuevos proyectos para una mejor adquisición de todas las lenguas y para una mayor facilidad de la poliglottia: construir, en fin, una lengua absolutamente nueva, absolutamente fácil, absolutamente racional y filosófica (más aún, pansófica), instrumento universal de la luz. (Comenio, 1996, p. 7)

Este proyecto de homogeneización, o de maximización de los canales de entendimiento, es la plataforma para establecer relaciones de tolerancia bajo una trascendencia fraternal e iluminista.

Si enseñáramos, aunque sea a un solo hombre, el camino recto de la sabiduría, de la virtud y de la salvación, este arte o prudencia sería suficiente para trasladar el mundo de las tinieblas a la luz, de los errores a la verdad, de la muerte a la salvación. (Comenio, 1992, pp. 59-60)

El reflejo del sueño agustiniano de una sociedad universal en paz, a través del progreso intelectual, moral y espiritual, es revestido de la duda cartesiana, del arte de desconfiar de Agrícola y de una esperanza renovada en los sentidos. Dicha manera de volver a mirar el cosmos se plasmará en El laberinto del mundo y el paraíso del corazón (1663).
Anteriormente, la obra Peregrini in Patria errores (1618), de Johan Valentin Andreae, dibuja con limpieza el sentir nómada que diseñará la arquitectura del Homo viator. En dicho trayecto, vital y literario, destaca en el pensamiento comeniano la influencia creciente del concepto de segunda naturaleza de Michel de Montaigne - que será fundamental para el retorno al estado de inocencia del buen salvaje roussoniano- como punto de reflexión para la construcción de un libre albedrío finito, silueta de un modelo de huésped en el laberinto-mundo.

Por último vi a la muerte caminando entre ellos en todas partes. Pertrechada con su afilada guadaña, un arco y una flecha, iba exhortando a todos a recordar que eran mortales. Pero nadie escuchaba su voz y todos seguían obrando sin pausa sus locuras y desórdenes. La muerte disparaba empero sus flechas en todas direcciones: cuando acertaba a alguien entre la multitud, igual daba si era joven o viejo, pobre o rico, sabio o necio, sin distinción alguna, entonces este caía al suelo. [...] Entonces tomaban al muerto, se lo llevaban a rastras y lo arrojaban fuera, a aquel oscuro abismo que rodeaba al mundo. Y cuando regresaban volvían a pegarse la gran vida, pero ninguno esquivaba las flechas de la muerte, sino que solo pensaban en no vérselas cara a cara con la muerte cuando esta les rondara. (Comenio, 2009, p. 115)

Comenio insiste en la participación de los padres, en la corrosión de esa segunda naturaleza, a través del fortalecimiento de las buenas costumbres desde dos aspectos que también deberán tener como fundamentales la escuela: la disciplina y las cualidades individuales del discípulo. Sobre ambas, muestra con crudeza cómo la primera se ha tornado en defensa de los privilegios materiales e intelectuales y las segundas, en moneda de cambio para una oxidada movilidad social.

Llegamos a la puerta llamada Disciplina: era larga, estrecha y oscura, llena de vigilantes armados; todos los que quisieran ir a la calle de los sabios debían presentarse ante ellos y solicitar la admisión. Y acudían montones de jóvenes que debían someterse a diferentes exámenes arduos. El primer examen de todos ellos consistía en una prueba para saber cómo era su bolsillo, cómo su trasero, cómo su cabeza, cómo su seso y cómo su piel. Si la cabeza era de acero y el seso de mercurio, las posaderas de plomo, la piel de hierro y el bolsillo de oro, los vigilantes alababan al candidato y solícitos lo acompañaban en su camino hacia delante; pero si a alguno le faltaba alguna de estas cosas, lo echaban para atrás o lo aceptaban de mala gana y con malos modales. Me quedé asombrado: “¿Qué hay tan importante para ellos en estos cinco metales?" - "Mucho, sin 
duda", respondió el Espejismo, "si alguien no tiene la cabeza de acero, le estallará; si en ella no tiene un seso fluido, no se podrá hacer un espejo con él; si no tiene una piel de chapa, no mantendrá las formas modeladas; si sus posaderas no son de plomo, no empollará, sino que lo desparramará todo; ¿y cómo conseguirá ya profesor, los libros escritos por autoridades, sin tener un bolsillo de oro? ¿0 es que te piensas que se pueden poseer cosas tan elevadas a costa de nada?" Con ello me quedó claro que para acceder a este estamento había que aportar salud, sagacidad, constancia, perseverancia y dinero. "Así pues", dije, "no todo el que quiere puede llegar a Corinto. No toda la madera se convierte en noble". (Comenio, 2009, pp. 135-136)

La segunda naturaleza, terriblemente arraigada a través de los dogmas eclesiásticos y populares (costumbrismo), es favorecida y expandida por una cultura del glosamiento que no han logrado desestabilizar ni los filósofos ni su osadía de pensar.

\begin{abstract}
Algunos salían huyendo de allí y otros se limitaban a exhortar que se tuviera cuidado en el trato con los libros. Por ello no se comían las cajitas, sobre todo aquellas en las que se leía vocabulario, diccionario, léxico, enciclopedia, antología, glosario, postilla, concordancia, herbario, etc., cada uno según su especialidad, sino que se lo metían en bolsas y mochilas que cargaban a pecho y espalda por delante y por detrás; si entonces querían decir o escribir algo, se sacaban de la cartera lo que correspondía, se lo metían en la boca o lo metían dentro de la pluma. (Comenio, 2009, p. 139)
\end{abstract}

En el capítulo XXXI, aparecen claras las referencias a la obra baconiana Nueva Atlántida y a su Casa Salomón, a través de la cual Comenio prosigue su estudio sobre la poca utilidad de las instituciones de su tiempo y también de las que emanaron. Una crítica paralela a la que expone Michel de Montaigne con la máxima sobre cabezas bien hechas frente a las bien llenas.

Pero yo quería, como siempre, ver qué iba a ser de aquella gente; me fijé en uno de aquellos doctores, al que le estaban mandando que calculara cierta cosa: pero no sabía; le mandaron medir, y no sabía; le mandaron nombrar las estrellas, y no sabía; le mandaron hacer silogismos, y no sabía; le mandaron hablar en otras lenguas, y no sabía; le mandaron disertar en su propia lengua, y no sabía; finalmente le ordenaron leer y escribir, y no sabía [...] A ver si he entendido bien: después de pasar un buen tiempo en la escuela, después de gastarse dinero y hacienda, después de recibir el título y el sello, hay que pregunta[...]r si realmente han aprendido algo. (Comenio, 2009, p. 167)
Toda la trama del laberinto, el viaje que parte con la Odisea de Homero y continúa con el descenso de Dante a los infiernos, llega ahora en pleno siglo XVII al momento en el cual el protagonista se quita las gafas y percibe la necesidad neoplatónica de reactualizar La república, en la que es fundamental no solo formar y distribuir al pueblo en una justa división social del trabajo. Lo primordial será la preparación y el mantenimiento de buenos gobernantes, pues, coincidiendo con los propios jesuitas y hasta con Maquiavelo, serán estos los modelos que habrán de extender las buenas costumbres, el amor a la sabiduría y los principios de responsabilidad comunitaria a través de la armónica creación de una red universal de escuelas pansóficas.

El fin último del hombre, hacia la excelsitud, requerirá de una naturaleza buena al modo de Pico della Mirandola y una educación que dé respuesta a la necesidad radical del cambio. Así pues, en el viaje vital del moravo, hemos pasado ya por la zona inestable y agónica del exilio y ahora nos aproximamos al espacio del confort, cuando bajo el auspicio de protectores, entre Suecia y Holanda va a sedimentar y condensar la plataforma que servirá de alimento a la Didáctica magna.

De rerum humanarum emendatione consultatio Catholica (1655) es un amplio tratado que emana de las reflexiones tras la finalización de la Guerra de los Treinta Años y desde donde advierte de los peligros y daños de entregarnos únicamente a la providencia. Promueve a través de la extensión de una conciencia colectiva que cada ser humano tiene el derecho y la obligación de crear y cambiar el mundo de acuerdo con sus ideas, y según su propia conciencia.

Dividido en siete libros, comienza con la Panegersia en la que insta a la humanidad a participar de una deliberación o consulta universal. Concibe intrínseco al ser humano el deber de participar de los problemas globales y considera que sin dicha participación el mismo humano se escinde de su derecho a la transcendencia. A la vez, intuye el peligro que supone dicho referéndum, en una centuria en la cual la caída del Sacro Imperio Germano supone un escenario conflictivo entre el deseo popular de regímenes democráticos y las ansias de la aristocracia por restablecer sus divinizados derechos de forma absoluta. Esto, trasladado hacia la cultura, le obliga a la prudencia para no recibir de inmediato el rechazo de las cúpulas intelectuales de su tiempo.

El segundo libro aborda la panaugía. Inspirado en la obra Nueva filosofía del universo, de Francesco Patrizi, emana de la división de la filosofía en panaugía como iluminación universal, panarquía o teoría sobre el origen de todo, y panpsiquia, relacionada 
con el alma y la pancosmia o la visión totalizadora del mundo. La herencia neoplatónica se estructura sobre la admisión de un primer principio unitario relacionado con la idea del bien, del cual, recordando los grados del ser de Ficino, se desgranan la sabiduría, la vida, el intelecto, el alma, la naturaleza, la cualidad, la forma y el cuerpo. Estos nueve órdenes inspirarán tanto los mundos como las escuelas que diseñará para la pampedia, concebida como un acto de amor que tiende al retorno del hombre hacia la unidad originaria. "Pampedia quiere decir el cultivo relacionado con cada individuo de todo el género humano. Ella se dirige con sus medidas, hacia lo universal [universalis] e introduce a los hombres en la perfección de su esencia [cultura]" (Comenio, 1992, p. 15). En palabras de Patrizi da Cherso (1993), el conocimiento humano proviene de la unión con el objeto cognoscible.

Para el moravo, la panaugía sería la eliminación de los prejuicios, la desnudez ingenua de horizontes y el adelgazamiento crítico del pasado, para permitir o propiciar una mirada clara y límpida que perciba la sabiduría como el medio de transporte directo y eficaz de las enmiendas del mundo. Esa luz, metafórica, está albergada en tres lámparas: Naturaleza, Mente y Escrituras. Recordando La docta ignorancia de Nicolás de Cusa, declara que el ser humano debe despertar de la indiferencia para poder alumbrar la razón y fortalecer la voluntad, ver con nuevos ojos la totalidad del cosmos para percibir la panharmonía.

Así que el tercer libro, De rerum humanarum emendatione consultatio Catholica, se centra justamente en este medio, la pansofía, la filosofía rectora del mismo programa de enmienda. Un concepto de sabiduría que ya detallamos y que se entiende como el arte de saborear, de aprehender a través de los sentidos y la experiencia de lo concreto a lo abstracto, de las cosas a las palabras. Sin duda, aprecia el valor de la cultura no por la cantidad o su peso nominativo; busca pues un espacio desde el que diseccionar un pasado corrupto que ha tornado al sabio en erudito.

La naturaleza humana, puesto que es toda ella activa, hacia cualquier lado que se vuelva se difunde; es por tanto capaz de ser educada. Esto es evidente porque la naturaleza humana es parte de la naturaleza universal, la cual no puede dejar de actuar, lo que se demuestra observando las actividades de todo lo natural.... Un rayo de sol si es recogido por un espejo se reflejará en la dirección que tú quieras, pero si no se le ofrece un espejo, él mismo incidiendo sobre las aguas se reflejará en todas las direcciones, o desparramará su luz sobre la tierra, los edificios, las selvas, las nubes, etc. Así ocurre con todas las cosas. (Comenio, 1992, p. 15)
Sin embargo, dicha acepción, que aparentemente podríamos ubicar en el plano de lo existencial, tiene su estructura en un funcionalismo, herencia de los principios mecanicistas que se extiende durante la centuria de la manufactura. Su crítica a las instituciones educativas, como estandartes del saber, tiene similitudes diacrónicas con los análisis de Rabelais en torno a unos studia humanitatis pantagruélicos; también con el nihilismo de Montaigne en referencia a unas escuelas donde se forjan hombres como monedas. Coincide profundamente —en lo pedagógico- con los jesuitas que entienden sus revolucionarias instituciones educativas como espacios para la exteriorización de la Pietas Literata, e incluso se concilia con Descartes a través de su reflexión sobre la inutilidad de muchas de las cosas que siguen siendo sagradas en las aulas. En resumen, todos comprenden que la cultura anquilosada solo mira maquiavélicamente al pasado y, codiciosa de su posición, niega el espacio a la interpretación, ofreciendo una sabiduría del glosamiento que engendra hombres anacrónicos y poco útiles para la construcción de proyectos de convivencia modernos.

Tanto en sus libros de texto, como en la propia concepción circular de la Didáctica magna, la pansofía tendrá relación con la idea de teatro, un lugar imaginario donde tienen cabida todas las cosas del mundo. Jugará a través de preciosas analogías a construir, a modo de espejos dentro de espejos, relaciones macro-micro en las que andarán sincrónicamente el individuo, la escuela y el cosmos. Dicha relación partirá de las edades del hombre (geniturae, infantiae, pueritae, adoliescientiae, juventutis, viritatis, senii y mortis) que tendrán su reflejo en el siguiente círculo, el de las instituciones educativas y, finalmente, en su representación cosmológica.

\section{Así como el mundo es una escuela para todo el género humano, desde el comienzo y hasta el final de los tiempos, así toda la vida es una escuela para cada individuo, desde la cuna a la tumba [...] Por ello todos los periodos de la vida y las tareas que hay por realizar en cada uno de ellos, deben ser dispuestos de tal modo que finalmente podamos decir de cada hombre que ha realizado su vida antes del fin de la misma y que se ha preparado para la venidera. (Comenio, 1992, pp. 117-119)}

Así pues, el mundus possibilis que se relaciona con la paternidad y la primera infancia es el mismo que permite o posibilita el resto de mundos. El destino de cada uno, es decir, el valor de su libertad y su capacidad de tornarse en sinónimo de utopía, tiene su medida en la voluntad, la inteligencia y el facere humano. Dicha oportunidad está dibujada en el mun- 
dus idealis seu archetypus que, en perfecta consonancia con los modelos fundadores jesuitas, se convierten en las líneas de referencia del carácter virtuoso para la convivencia en el mundo y el desarrollo personal hacia el otro.

El tercer mundo, que representa al niño a partir de seis años y a la escuela de letras, es el mundus intelligibilis angelicus, el espacio de la restauración en el cual, frente a las constantes en la historia de enseñar al alumno a leer y a escribir a través de los grandes textos, se hará prioritario la formación del carácter y del juicio. La bondad natural configura la base antropológica que debería ayudar al humano a emanciparse de los errores del pasado y, posicionarse en el presente, dispuesto a reconstruirlo.

Por ello, el cuarto círculo, el de la adolescencia, tiene una amplia relación con lo artesanal, con los oficios. El mundus materiales seu corporeus concibe al humano como usufructuario y conservador de los bienes naturales. Es decir, que el humano bueno y consciente de su situación gradual en el mundo se predispone para el quinto círculo, el mundus artificialis de la industria y de las manos, el material, el que responde al mecanicismo manufacturero. Aquí se pergeña la división social del trabajo y también se organizan las diferentes esferas de la actividad transformadora del ser humano sobre su ambiente y sobre sí mismo. El objetivo es la eliminación de la pereza y de la pobreza a través de la ocupación coherente del tiempo vital de cada individuo mediante una pedagogía que inspire un sentimiento profundo de utilidad social a cada acto.

Es muy importante para la humanidad que la gente llegue a ser industriosa y amante del trabajo [...] Porque, si cada uno sigue su trabajo, callado, y todos, siendo aplicados, tienen suficiente, allí nadie es pobre, ni hay tiempo para bribonadas. (Comenio, 1996, pp. 173-174)

Si bien los cinco primeros mundos pertenecen al terreno de la inmanencia manufacturera del siglo XVII, los tres siguientes conformarán la superestructura. El mundus moralis se referirá a la ética y al arte de gobernar, es decir, será la actualización de la virtud ciceroniana a través de los principios del estoicismo y el epicureísmo; la prudencia se erige rectora del hombre entre los hombres. Y en este sendero hacia la transcendencia, aparece el séptimo círculo, que se asocia con la senectud, y que bautizado mundus spiritualis, será el que represente lo religioso del ser. En esta reconstrucción aparece la profunda crítica a las iglesias como carceleras de la fe, la esperanza y la caridad. Este círculo sin duda está relacionado con el concepto de pietas y emana de la actualización que realizarán en el siglo XVI los jesuitas al concepto de tradición.

El último espacio, que cierra el libro IV, es el mundus aeternus que se concibe como el leitmotiv de todos los anteriores, al estilo Michel de Montaigne, entendiendo la vida como un tránsito hacia la muerte. Así queda esbozada la Pampedia, la obra que servirá de marco general para la Didáctica magna. El resto de la consulta se cierra con tres libros de los cuales o ya hemos realizado las correspondientes referencias, o se alejan de lo perseguido en la investigación. El quinto libro gira en torno al lenguaje universal y la configuración de la panglotia, el sexto titulado Panorthosia (restauración universal) y, finalmente, la Panuthesia, desde la que, igual que comienza, insta a colaborar a todos los seres humanos en esta reforma para alcanzar la plenitud y la concordia.

\section{In-conclusiones: veinte lecciones de la didáctica magna}

Ya finalizada - provisionalmente- la revisión de la magna obra de Comenio, tenemos a nuestra espalda el crepúsculo de un humanismo agonizante y al frente, el amanecer de un proyecto de modernidad que, anegado por el instintivismo roussoniano, menguará deber y disciplina para confiar en la libertad como verdadero motor para la construcción de sociedades abiertas (Karl Popper) y en equilibrio con el entorno:

- Comenio fluctúa entre los paradigmas mecanicista y teleológico como reacción a un humanismo aniquilado y un proyecto de trascendencia cristiana jesuita anclado en el siglo XVI.

- El hombre que se pretende forjar en la Didáctica magna nace de integrar el libre albedrío de Pico della Mirandola y la actualización de la Devotio Moderna de Erasmo de Rotterdam. Tomando el dégré zero aristotélico se entiende que su bondad natural lo torna en un animal disciplinable que, sin la misma, anticipa a John Locke la idea de considerarlo el animal más fiero de la Tierra.

- El estoicismo como superestructura del atomismo se transforma en el siglo XVI en mecanicismo. Desde aquella percepción del mundo se establece una analogía macro-micro que convierte el orden del universo en el modelo de funcionamiento óptimo de todas las cosas. La causa y efecto establecen entonces que el camino directo, desde lo real a lo deseado, es el método. 
- El realismo pedagógico, en el que podemos entender el pensamiento de Juan Amós, se fundamenta en considerar la vida humana tan miserable como divina y en establecer que el sujeto educado, a través de un sentimiento de resignación positiva y de sus acciones, participa de su destino en el mundo y en el más allá.

- El iluminismo que inspira al moravo es el precedente de la Ilustración, es decir, el sendero de divinización de la razón hasta asemejar la trascendencia al intelecto.

- La manufactura exige un modelo de ciudadano con claras habilidades instrumentales y, sobre todo, con capacidad de adaptación al cambio. La educación no es para toda la vida, sino para la vida. Debe comenzar pronto y terminar bien para que el sujeto produzca de forma efectiva el mayor tiempo posible. Se esboza el concepto de capital humano en educación.

- La selección de ingenios de Quintiliano se prolonga al acceso a la Academia. En defensa de los entendimientos intermedios, Comenio plantea una enseñanza general para todos que comienza desde la familia y la Gremium Materne hasta la Escuela Latina, sin mayor delimitador de grupos que la edad.

- La gran novedad estructural del sistema planteado en la Didáctica magna, contenida en las obras que giran en torno a la panglotia, está sustentada en el desarrollo de los sentidos por medio de la intuición, con el fin de iniciar al alumno en una cultura general a través de su propia lengua. El objetivo, conseguir con eficacia un sentimiento de responsabilidad patriótica y construir un modelo de identidad colectiva.

- La crítica a las escuelas de Lutero sirve de marco para que Comenio entienda que estas no tienen coherencia entre medios y fin y por ello, confíe en la necesidad de que estas sean útiles; es decir, produzcan hombres que mejoren de forma práctica y a través de las obras, el mundo que los rodea.

- La propia escuela debe ser un lugar agradable, tanto que el discípulo la considere su segundo hogar. Desde el propio diseño arquitectónico hasta los accesorios didácticos, los libros o los horarios deben favorecer la convivencia de lo serio con lo lúdico.

- Tal laxitud se establece en la enseñanza de las ciencias, las letras y las artes, en las cuales prima el sensualismo, la imitación y la graduación.
- La disciplina aparece sólidamente en la enseñanza de las costumbres y la piedad. Prudencia, fortaleza, templanza, constancia y justicia son los vértices del concepto de deber que osamenta la construcción del hombre autónomo. Este hombre, a través de la meditación, la oración y la tentación, será capaz de intervenir en la vida colectiva como un ser piadoso.

- El maestro comeniano es el alma de la escuela. El artífice que convierte el conocimiento en algo deseable y el aula en un espacio para el disfrute y a la vez, un experto capaz de organizar, analizar y aplicar el método y sus instrumentos con la precisión de un cirujano.

- El método descrito en la Didáctica magna se establece fisiológicamente sobre la máxima de Juvenal de prolongar la vida a través de hábitos sanos. Aparecen aquí principios estoicos y epicúreos.

- Para aprender a enseñar, el maestro debe entender que la instrucción es un arte que observa con humildad las leyes de la naturaleza. Aprovecha el tiempo favorable, prepara la materia antes de empezar a darle forma, no confunde sus obras, comienza sus operaciones por lo interno, va de lo general a lo particular, procede gradualmente, evita lo contrario y lo nocivo y no se detiene hasta que su obra está finalizada.

- La facilidad para enseñar y aprender comprende el establecimiento de una disciplina temprana, motivación, implicación de la familia en el proceso, sencillez, gradación, austeridad, paciencia, claridad de los objetivos, utilidad y uniformidad mesológica.

- La solidez para aprender y enseñar se sustenta en una relación coherente inmanencia-trascendencia. Desde un racionalismo sensorial se busca imprimir en la memoria lo esencial, es decir, que el discípulo conozca las cosas por sus causas y que este, bien motivado, sea capaz de pedir, retener y enseñarlas.

- La abreviada rapidez de la enseñanza precisa de un maestro para cualquier número de discípulos, libros escolares para instruirlos a todos, la utilización del diálogo junto con ilustraciones y ejemplos, la sincronización de temario y horarios, un método único natural, muchas cosas con pocas palabras, interrelaciones, secuenciación y utilidad de estas. 
- La dificultad aparece en el sendero de la sabiduría. Camino a la Academia, donde solo llegarán los mejores, no existen atajos. Aparece nuevamente la matriz platónico-agustiniana para esbozar la necesidad de un gobierno de los mejores sobre un pueblo educado en la medida de un entendimiento intermedio.

- Comenio prosigue un largo proceso iniciado por Quintiliano, cuestionado por Montaigne y estructurado por los jesuitas, que podremos entender como la matriz del sistema tradicional de enseñanza y, a la vez, propicia la base epistemológica para el surgimiento a través de Rousseau, Pestalozzi y Fröebel, del sistema liberal de enseñanza decimonónico.

\section{Referencias}

Aquino, T. (2005). Cuestiones disputadas sobre la verdad. Biblioteca Nueva S.L.

Belenguer, E. y González, M.L.C. (1988). Dios, método y orden: Comenio o la fundamentación de la enseñanza tradicional. Revista de Historia de la Educación. Interuniversitaria, 7, 123 -135.

Cicerón, M. T. (1999). Sobre la naturaleza de los dioses. Gredos S.A.

Comenio, J. A. (1991). Didáctica magna. Porrúa S.A.

Comenio, J. A. (1992). Pampedia. UNED.
Comenio, J. A. (1993). El mundo sensible en imágenes. Consejo Nacional de Ciencia y Tecnología; Miguel Ángel Porrúa.

Comenio, J. A. (1996). Páginas escogidas. A.z. Editorial; Orcalc/Unesco.

Comenio, J. A. (2009). El laberinto del mundo, el paraíso del corazón. Biblioteca Nueva S.L.

Galán Rodríguez, C. (1996): La invención de lenguas en la ficción literaria. Investigaciones lingüísticas en el siglo XXI, 103-129.

Hipona, A. (2006). La ciudad de Dios. Homo Legens.

Lora, M. E. (1997). Caleidoscopios comenianos. Plaza y Valdés; UNAM.

Lutero, M. (1986). A la nobleza cristiana de la nación alemana. En Escritos Políticos. Tecnos.

Paz, O. (1990): La búsqueda del comienzo: escritos sobre el surrealismo. Fundamentos.

Platón. (2003). Timeo. Alianza S.A.

Seijas, C. L. (1991). La escolarización. Historia de la enseñanza. Montesinos.

Patrizi da Cherso, F. (1993). Nova de Universis Philosophia. Materiali Per Un'edizione Emendata. Casa Editrice Leo S. Olschki,

Vives, J. L. (2010). Introducción a la sabiduría. El Sabio. Akal S.L. 